\title{
PERAN PROMOSI MEDIA SOSIAL PADA PEMILIHAN PROGRAM STUDI MANAJEMEN BISNIS SYARIAH
}

\author{
Oleh \\ Yulfan Arif Nurohman ${ }^{1)}$, Alvin Yahya ${ }^{2)}$ \\ IAIN Surakarta \\ Rina Sari Qurniawati ${ }^{3)}$ \\ STIE AMA Salatiga
}

\begin{abstract}
For two consecutive years the Islamic Business Management Study Program (MBS) of IAIN Surakarta received an award from SPAN-UM PTKIN (National Academic Achievement Selection - State Islamic Religious College Entrance Examination) in the highest number of applicants in the State Islamic Institute (IAIN) category. The selection of the right study program is a hope for prospective students as a provision for the future. Various sources of information are sought to obtain information related to study programs. The development of information technology makes social media a tool used in marketing. Respondents in this study were 101 Islamic Business Management Study Program students. Data collection techniques using survey methods by giving questionnaires to respondents. In testing the research model, researchers used descriptive analysis methods and linear regression on the SPSS statistical program to test the validity, reliability and research hypothesis. The results of the study show that there is a relationship between the role of social media promotion in the selection of study programs. This is shown in the variables of personal relevance, message and brand familiarity, there is a positive influence on the selection of study programs. So, it can be said that the official social media accounts owned by IAIN Surakarta Syariah Business Management Study Program (MBS) can build trust in their followers to keep up with the latest information through social media so as to increase value.
\end{abstract}

Keywords : media sosial, personal relevance, interactivity, message, brand familiarity

\section{PENDAHULUAN}

Penghargaan diberikan kepada Program Studi Manajemen Bisnis Syariah IAIN Surakarta sebagai program studi dengan jumlah peminat terbanyak kategori Institut Agama Islam Negeri (IAIN) secara nasional pada seleksi ujian masuk Perguruan Tinggi Keagamaan Islam Negeri Tahun 2017 dan 2018. Penghargaan ini diberikan oleh SPANUM PTKIN (Seleksi Prestasi Akademik Nasional-Ujian Masuk Perguruan Tinggi 
Keagamaan Islam Negeri). Penghargaan yang didapatkan menjadi bukti bahwa Program Studi Manajemen Bisnis Syariah IAIN Surakarta menjadi salah satu program studi yang diminati oleh calon mahasiswa baru di Indonesia.

Program Studi Manajemen Bisnis Syariah (MBS) merupakan salah satu program studi di Fakultas Ekonomi dan Bisnis Islam (FEBI) IAIN Surakarta. MBS merupakan program studi pertama di FEBI. Jumlah pendaftar di Program Studi Manajemen Bisnis Syariah terus mengalami peningkatan tiap tahun. Hal ini dibuktikan dengan data pendaftar calon mahasiswa baru lima tahun terakhir pada tabel 1.

Tabel 1. Daftar Pendaftar Calon Mahasiswa Baru Program Studi Manajemen Bisnis Syariah

\begin{tabular}{|c|c|c|c|c|}
\hline TAHUN & $\begin{array}{c}\text { JALUR SPAN } \\
\text { PTKIN }\end{array}$ & $\begin{array}{c}\text { JALUR } \\
\text { UMPTKIN }\end{array}$ & $\begin{array}{c}\text { JALUR } \\
\text { MANDIRI }\end{array}$ & JUMLAH \\
\hline 2018 & 2883 & 996 & 0 & 3879 \\
\hline 2017 & 1739 & 655 & 0 & 2394 \\
\hline 2016 & 1233 & 614 & 919 & 2766 \\
\hline 2015 & 933 & 580 & 739 & 2252 \\
\hline 2014 & 699 & 388 & 372 & 1459 \\
\hline 2013 & 18 & 253 & 0 & 271 \\
\hline
\end{tabular}

Sumber: Biro Umum IAIN Surakarta 2018

Kemajuan teknologi membuat masyarakat lebih mudah memperoleh informasi. Perkembangan internet menjadikan informasi lebih cepat diakses oleh masyarakat. Di Indonesia terdapat 143 juta pengguna internet dengan lama penggunaan lebih dari tujuh jam mencapai 26,48\%. Waktu yang dihabiskan dalam mengakses internet memiliki jangka waktu yang sama dengan jam kerja karyawan. Artinya, masyarakat saat ini telah tergantung oleh perkembangan teknologi dan kemajuan internet, bahkan Indonesia menempati peringkat ke enam pada pengguna internet didunia.

Berdasarkan data Kominfo dan APJII (2016) di Indonesia tercatat terdapat 132,7 juta orang pengguna internet dan media sosial, terdiri dari 3 juta blogger yang belum 
termasuk youtuber dan vlogger. Selain itu juga tercatat ada 129 juta media sosial aktif meliputi facebook, twitter, instagram dan google+. Jumlah pengguna facebook di Indonesia menempati peringkat 4 besar dunia, sedangkan pengguna twitter di Indonesia menempati peringkat 5 besar dunia. Penggunaan media sosial menjadi tren dikalangan masyarakat Indonesia (Sikape, 2014).

Penggunaan media sosial merambah sebagai alternatif dalam melakukan kegiatan pemasaran. Pada tahun 2016 di Indonesia terdapat 129 juta pengguna aktif media sosial, hal ini menjadi peluang bagi pemasar untuk memberikan informasi dan upaya pemasaran kepada pengguna media sosial. Usaha yang dilakukan untuk memasarkan produk dan jasa menggunakan media internet disebut E-Marketing (Kotler dan Amstrong, 2008). EMarketing merupakan sisi pemasaran yang terdiri dari usaha yang dilakukan oleh perusahaan untuk berkomunikasi, mempromosikan serta menjual barang dan jasa melalui internet.

Program studi harus mampu memberikan informasi secara efektif dan efisien. Kecepatan arus informasi yang diberikan berpengaruh terhadap respon mahasiswa. Menurut Barnett Pearce (1989) komunikasi merupakan penemuan revolusioner yang disebabkan oleh kemajuan teknologi komunikasi melalui televisi, radio, satelit dan jaringan komputer. William (1992) dalam buku berjudul The New Communications menyatakan bahwa teknologi telah mengubah cara berkomunikasi perseorangan, grup, organisasi, publik dan komunikasi internasional. Perkembangan teknologi memudahkan mahasiswa dalam memperoleh informasi melalui media sosial. Nurohman dan Qurniawati (2017) menyatakan bahwa konten media sosial dapat menciptakan respon dalam menyebarkan promosi publik. Dukungan media sosial diharapkan mampu mengoptimalkan fungsi pemasaran.

Beberapa universitas di Surakarta memiliki program diacara stasiun televisi lokal dengan tujuan sebagai bentuk memberikan informasi terkait program studi yang dimiliki. Berdasarkan data Reuters Institute: Digital News Reports (2017) media sosial menjadi pencarian yang lebih banyak dalam mencari informasi (berita) dibandingkan televisi pada generasi muda dengan rentang usia antara 18 - 24 tahun. Kecenderungan generasi muda 
menggunakan media sosial sebagai rujukan mencari informasi menjadi peluang bagi program studi untuk membagikan informasi.

Setiap perguruan tinggi menganggap bahwa pemahaman makna promosi merupakan hal yang penting bagi bagian pemasaran atau para pimpinan perguruan tinggi. Promosi dari produk pendidikan mengharuskan SDM pada perguruan tinggi tersebut bekerja secara profesional dalam pelayanan maupun aktivitasnya. Hal ini akan berdampak pada tercapainya target jumlah mahasiswa yang diinginkan setiap tahunnya. Untuk menghadapi pergembangan teknologi khususnya di bidang internet, perguruan tinggi harus memiliki strategi untuk menghadapinya. Pada Program Studi MBS IAIN Surakarta, faktor promosi menjadi poin penting dalam menyampaikan keunggulan yang dimiliki karena begitu ketatnya dalam merekrut mahasiswa baru dan dengan banyaknya pilihan proram studi yang ditawarkan. Berdasarkan latar belakang yang telah dikemukakan sebelumnya maka rumusan masalah dalam penulisan ini adalah sebagai berikut :

1. Apakah variabel personal relevance berpengaruh signifikan terhadap keputusan mahasiswa dalam memilih Program Studi MBS IAIN Surakarta?

2. Apakah variabel interactivity berpengaruh signifikan terhadap keputusan mahasiswa dalam memilih Program Studi MBS IAIN Surakarta?

3. Apakah variabel message berpengaruh signifikan terhadap keputusan mahasiswa dalam memilih Program Studi MBS IAIN Surakarta?

4. Apakah variabel brand familiarity berpengaruh signifikan terhadap keputusan mahasiswa dalam memilih Program Studi MBS IAIN Surakarta?

\section{METODE PENELITIAN}

Tipe penelitian ini adalah tipe penelitian deskriptif yaitu tipe penelitian yang bertujuan untuk memberikan gambaran mengenai subjek penelitian berdasarkan data variabel yang diperoleh dari subjek yang diteliti dan dimaksudkan untuk pengujian hipotesis (Azwar, 2000:56). Populasi pada penelitian ini adalah mahasiswa Program Studi Manajemen Bisnis Syariah (MBS) angkatan masuk tahun 2017 dan 2018. Metode pemilihan sampel (sampling) dalam penelitian ini dilakukan secara non probability 
dengan teknik purposive sampling. Selain karena keterbatasan waktu, tenaga, dan biaya, alasan utama pengambilan sampel dilakukan secara non probability ialah karena dalam penelitian ini peneliti tidak memiliki list anggota populasi dari pelajar yang akan dijadikan sampel.

Adapun ukuran sampel yang akan digunakan, ditentukan berdasarkan pada Roscoe (1975) yaitu ukuran sampel sebaiknya 10x lebih besar dari jumlah variabel dalam penelitian. Namun, untuk menghindari resiko adanya unit sampel yang cacat dan tidak dapat diolah, maka ukuran sampel yang direncanakan adalah sebanyak 101 responden.

\section{KAJIAN TEORITIS}

\section{Promosi Melalui Media Sosial}

Saat ini, dunia pemasaran digerakkan oleh teknologi internet dimana situs media sosial telah menjadi tempat dimana perusahaan dapat memperluas promosi mereka ke berbagai konsumen yang lebih luas. Definisi media sosial adalah teknoligi yang berbasis web dan mobile yang diciptakan untuk platform interaktif tinggi melalui individu dan komunitas yang saling berbagi, berdiskusi, co-create dan mengunah content yang dihasilkan oleh pengguna (Kietzmann, Hermkens, McCarthy, \& Silvestre, 2011).

Media sosial telah berkembang dari sekedar sebagai platform komunikasi antar keluarga dan teman menjadi tempat dimana para konsumen dapat mengenal lebih jauh tentang produk yang mereka senangi. Pemasar khususnya perguruan tinggi perlu memanfaatkan situs-situs ini sebagai cara baru untuk menjangkau mahasiswa baru. Melalui penggunaan media sosial, memungkinkan aktivitas pemasasaran terintegrasi dengan usaha dan biaya yang lebih rendah dari sebelumnya (Kim dan Ko, 2011).

Era media sosial secara pelan namun pasti telah 'memaksa' banyak perusahaan mengubah cara mereka berkomunikasi. Maraknya penggunaan media sosial misal: Facebook, Twitter dan instagram mau tak mau memaksa perguruang tinggi meningkatkan model ber-komunikasi. Perangkat media sosial ini adalah hal yang lumrah selalu bersentuhan dengan aktivitas kita terutama bagi para pengguna internet. Kertajaya (2010) menyatakan bahwa pola komunikasi pada internet berbasis media sosial bersifat horizontal. Konsumen lebih mempercayai informasi yang diberikan oleh konsumen lain 
dibandingkan dengan dengan bentuk komunikasi searah yang dijalankan oleh perusahaan selama ini.

Promosi merupakan salah satu unsur dari bauran pemasaran (marketing mix), disamping penetapan harga jual, produk, dan distribusi. Promosi sangat berpengaruh terhadap usaha perusahaan untuk mencapai volume penjualan yang maksimal, karena meskipun produk yang

ditawarkan sudah baik, relatif murah serta mudah untuk diperoleh, jika tidak disertai promosi yang baik, maka tingkat penjualan tidak akan memadai. Suatu usaha jika ingin mencapai tingkat penjualan yang maksimal, perusahaan dapat memakai beberapa macam bauran promosi (Kotler,

2002:644) yaitu : periklanan (Advertising), promosi penjualan (Sales promotion), hubungan masyarakat dan publisitas (Public relations), penjualan personal (Personal selling), dan pemasaran

langsung (Direct marketing). Namun dari semua hal yang diharapkan dari promosi, perlu pula dipertimbangkan apakah biaya yang dikeluarkan oleh kegiatan promosi itu dapat memberikan pengaruh yang besar terhadap peningkatan penjualan dan sampai sejauh mana promosi itu dapat menarik konsumen untuk membeli produk yang ditawarkan.

\section{a. Personal Relevance}

Personal relevance mampu mempengaruhi perilaku seseorang terhadap keputusan pembelian melalui media online. Dilihat dari penelitian yang dilakukan, Mereka mendapatkan hasil bahwa personal relevance memiliki pengaruh pada proses pengambilan keputusan konsumen secara individual. Menurut Cambell dan Wright (2008) indikator dari personal relevance yaitu, Initiative, Trust, dan Relationship

\section{b. Online Interactivity}

Tjiptono, Chandra (2012: 381) Online interactive memungkinkan tingkat keterlibatan pelanggan yang tinggi para pengunjung situs tertentu biasanya adalah mereka yang cukup tertarik pada perusahaan atau produk yanng dikunjungi situsnya. Indikator Online Interactivity yaiut intensitas interaksi dan interaksi pasca pembelian. 


\section{c. Pesan (Message)}

Faktor pesan sangat penting dalam membuat sebuah iklan di internet. Dalam promosi melalui media sosial, pesan adalah informasi yang dapat menarik perhatian konsumen. Tjiptono, Chandra (2012: 381) menyatakan bahwa Message yakni pesan bisa dirancang khusus sesuai dengan kebutuhan dan keinginan spesifikasi audiens sasaran.

\section{d. Brand Familiarity}

Brand Familiarity mengacu pada sejauh mana konsumen memiliki kedekatan langsung maupun tidak langsung dengan merek (M.C. Cambell \& Keller, 2003). Konsep ini merupakan konstruk multi dimensi yang berkaitan dengan berbagai pengalaman yang dimiliki konsumen dengan merek. Ukuran kedekatan konsumen dengan brand dimana sebuah brand yang cukup dikenal akan mendapatkan respon positif dibandingkan brand baru. Indikator Brand Familiarity adalah : well known, asosiasi merek dan ciri khas yang membedakan produk.

\section{Keputusan Pemilihan}

Kotler (2008: 63) menyatakan Pengertian keputusan pembelian adalah tahap dalam proses pengambilan keputusan pembeli dimana konsumen benar-benar membeli. Pengambilan keputusan merupakan kegiatan indifidu yang secara langsung terlibat dalam mendapatkan dan menggunakan barang yang di tawarkan. Hawkins, et. al (2004) bahwa hanya ada dua faktor utama yakni faktor eksternal yang terdiri dari : budaya (culture), sub-budaya (sub-culture), demografis (demographics), status sosial (sosial status), kelompok rujukan (reference group), keluarga (family) dan kegiatan pemasaran (marketing activities). dan faktor internal terdiri dari : persepsi (perception), pembelajaran (learning), memory (memory), motivasi (motives), kepribadian (personality), emosi (emotions) dan sikap (attitudes) sebagai penentu utama dalam menentukan keputusan pembelian

Keputusan pembelian merupakan keputusan konsumen untuk membeli suatu produk setelah sebelumnya memikirkan tentang layak tidaknya untuk membeli produk itu dengan mempertimbangkan informasi-informasi yang ia ketahuidengan realitas tentang produk itu setelah ia menyaksikannya. Kita dapat membedakan lima peran yang dimainkan orang dalam keputusan pembelian: 
a) Pencetus: Orang yang pertama kali mengusulkan gagasan untuk membeli produk atau jasa.

b) Pemberi pengaruh: Orang yang pandangan atau sarannya mempengaruhi keputusan.

c) Pengambil keputusan: Orang yang mengambil keputusan mengenai setiap komponen keputusan pembelian-apakah membeli, tidak membeli, bagaimana cara membeli, dan dimana akan membeli.

d) Pembeli: Orang yang melakukan pembelian yang sesungguhnya.

e) Pemakai: Seseorang yang mengkonsumsi atau menggunakan produk atau jasa tertentu

Untuk memenuhi pola baru konsumsi oleh konsumen dikembangkan suatu model komunikasi pemasaran untuk mempengaruhi konsumsi dari khalayak. Model yang dibentuk untuk menjawab pola konsumsi serta komunikasi pemasaran yang memberikan dampak terhadap khalaya di era media baru yaitu attention, interest, search, action dan Share.

\section{HIPOTESIS}

Menurut Bashar, Ahmad dan Wasiq (2012) media sosial sangat memberikan informasi serta mempengaruhi keputuasan pembelian. Hal ini disebabkan saat ini penggunaan media sosial lebih percaya terhadap opini rekan atau pihak lain daripada strategi pemasaran yang langsung dari perusahaan dalam memutuskan pembelian. Hutter, Hauzt, Dennhardt dan Fuller (2013) menyatakan bahwa kegiatan media sosial memang mempengaruhi proses pengambilan keputusan pembelian. Penelitian yang dilakukan Azmar dan Laksamana (2018) menyatakan bahwa informasi berupa pesan yang di posting di akun media sosial mampu menarik perhatian calon mahasiswa karena memiliki daya tarik, informasi yang jelas, dan mudah dipahami serta format pesan dan visualisasi gambar yang diposting cukup menarik. Berdasarkan rumusan masalah yang ditetapkan maka hipotesis yang diberikan peneliti adalah:

H1: Terdapat pengaruh positif antara Personal Relevance dengan keputusan pemilihan

H2: Terdapat pengaruh postitif antara Interactivity dengan keputusan pemilihan

H3: Terdapat pengaruh positif antara Message dengan keputusan pemilihan 
H4: Terdapat Pengaruh positif antara Brand Familiarity dengan keputusan pemilihan

\section{METODOLOGI PENELITIAN}

Penelitian ini adalah penelitian deskriptif kuantitatif dengan jenis penelitian asosiatif. Penelitian ini dilakukan di kampus Manajemen dan Bisnis Syariah (MBS) IAIN Surakarta yang dimulai dari bulan September - November 2018. Sistem pengolahan data yang dilakukan dalam penelitian ini adalah dengan menggunakan skala Likert yaitu teknik pengukuran sikap dimana subjek diminta untuk mengindikasi tingkat kesetujuan atau ketidaksetujuan merek terhadap masing- masing pernyataan.

Dalam penelitian ini peneliti melakukan analisis data dengan menggunakan SPSS versi 16.0. metode analisis yang digunakan adalah metode analisis deskriptif dan regresi linier. Regresi linier digunakan untuk melihat besar pengaruh variabel independe terhadap variabel dependen yang diuji.

\section{HASIL DAN PEMBAHASAN}

\section{Tabel 1}

Uji Validitas

\begin{tabular}{|l|l|l|l|}
\hline \multicolumn{1}{|c|}{ Item } & \multicolumn{1}{c|}{ rhitung } & \multicolumn{1}{c|}{ rtabel } & \multicolumn{1}{c|}{ Hasil } \\
\hline PR1 & 0.408 & 0.196 & Valid \\
\hline PR2 & 0.344 & 0.196 & Valid \\
\hline PR3 & 0.564 & 0.196 & Valid \\
\hline INTERACT1 & 0.633 & 0.196 & Valid \\
\hline INTERACT2 & 0.653 & 0.196 & Valid \\
\hline INTERACT3 & 0.234 & 0.196 & Valid \\
\hline MESSAGE1 & 0.719 & 0.196 & Valid \\
\hline MESSAGE2 & 0.736 & 0.196 & Valid \\
\hline MESSAGE3 & 0.774 & 0.196 & Valid \\
\hline BF1 & 0.705 & 0.196 & Valid \\
\hline BF2 & 0.635 & 0.196 & Valid \\
\hline BF3 & 0.551 & 0.196 & Valid \\
\hline KEPUTUSAN1 & 0.691 & 0.196 & Valid \\
\hline KEPUTUSAN2 & 0.589 & 0.196 & Valid \\
\hline KEPUTUSAN3 & 0.547 & 0.196 & Valid \\
\hline KEPUTUSAN4 & 0.434 & 0.196 & Valid \\
\hline KEPUTUSAN5 & 0.524 & 0.196 & Valid \\
\hline KEPUTUSAN6 & 0.545 & 0.196 & Valid \\
\hline SUTH : D
\end{tabular}

Sumber : Data primer diolah (2018) 
Dari tabel 1 diatas, dapat dilihat bahwa semua pertanyaan pada kuesioner mampu untuk mengungkapkan sesuatu yang akan diukur dalam penelitian ini atau dengan kata lain adalah valid. Dalam hal ini dapat dibuktikan dengan semua nilai $r$ hitung lebih besar dari nilai $r$ tabel.

Tabel 2

Uji Reliabilitas

\begin{tabular}{|l|c|c|}
\hline \multicolumn{1}{|c|}{ Variabel } & Cronbach's Alpha & Hasil \\
\hline Personal Relevance (X1) & 0.650 & Reliabel \\
\hline Interactivity (X2) & 0.634 & Reliabel \\
\hline Message (X3) & 0.881 & Reliabel \\
\hline Brand Familiarity (X4) & 0.760 & Reliabel \\
\hline Keputusan Pemilihan (Y) & 0.792 & Reliabel \\
\hline
\end{tabular}

Sumber : Data primer diolah (2018)

Seluruh item variabel yang digunakan adalah reliabel, yaitu dimana untuk masingmasing item variabel mempunyai nilai Koefisian Alpha lebih dari 0,06 seperti yang terlihat pada tabel 2 . Artinya bahwa alat ukur ini mampu menghasilkan data yang dapat dipercaya.

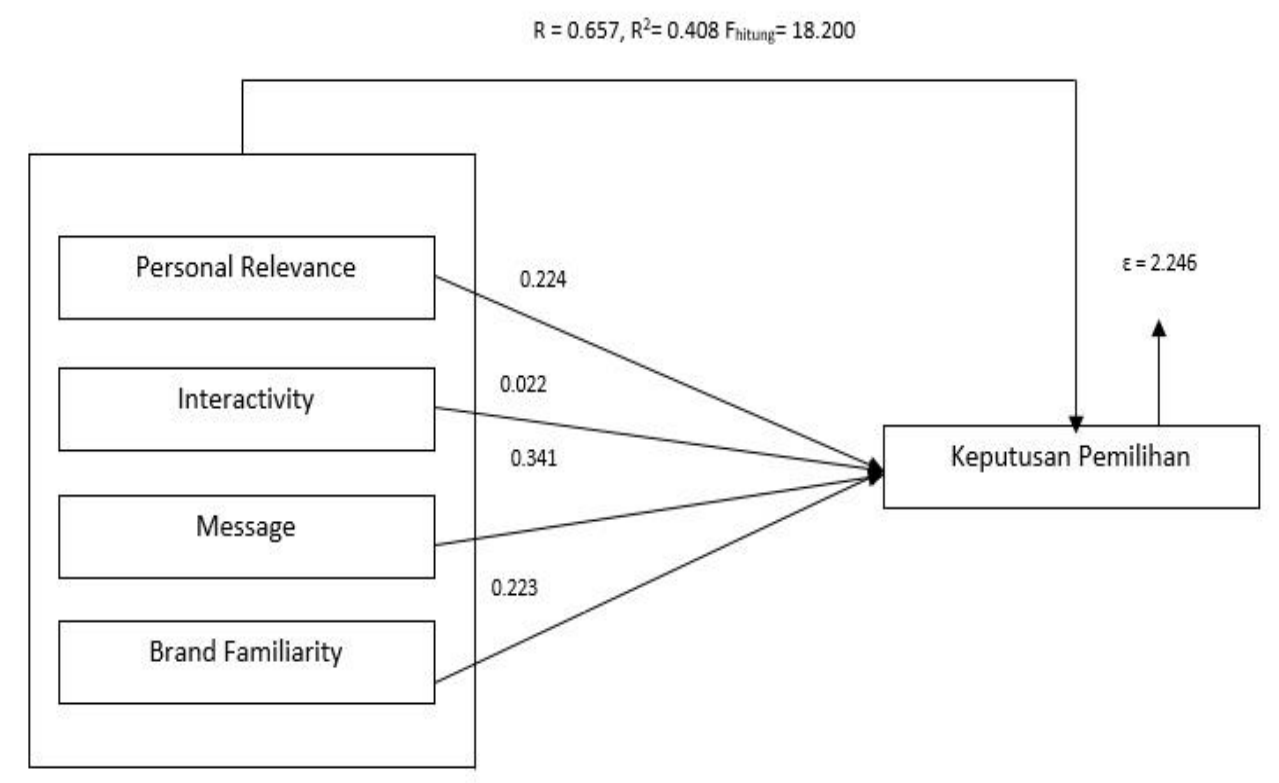

Gambar 2

Hasil Analisis Model Riset

Peran Promosi Media Sosial Pada Pemilihan Program Studi Manajemen Bisnis Syariah (Yulfan Arif Nurohman, Alvin Yahya, Rina Sari Qurniawati) 
Tabel 3

Analisa Hasil Uji Hipotesis

\begin{tabular}{|c|l|c|c|}
\hline \multicolumn{1}{|c|}{ Hipotesis } & Sig. & Hasil \\
\hline H1 & $\begin{array}{l}\text { Terdapat pengaruh positif antara personal } \\
\text { relevance dengan keputusan pemilihan }\end{array}$ & 0.014 & Diterima \\
\hline H2 & $\begin{array}{l}\text { Terdapat pengaruh postitif antara } \\
\text { interactivity dengan keputusan pemilihan }\end{array}$ & 0.839 & Ditolak \\
\hline H3 & $\begin{array}{l}\text { Terdapat pengaruh positif antara Message } \\
\text { dengan keputusan pemilihan }\end{array}$ & 0.004 & Diterima \\
\hline H4 & $\begin{array}{l}\text { Terdapat Pengaruh positif antara Brand } \\
\text { Familiarity dengan keputusan pemilihan }\end{array}$ & 0.043 & Diterima \\
\hline
\end{tabular}

Catatan:* Nilai signifikansi pada 0,005

Hasil penelitian menunjukkan bahwa terdapat pengaruh positif dan signifikan antara personal relevance terhadap keputusan pemilihan jurusan MBS. Dengan demikian dapat dikatakan bahwa akun resmi media sosial yang dimiliki oleh MBS IAIN Surakarta dapat membangun kepercayaan terhadap para pengikutnya untuk mengikuti informasi terbaru melalui media sosial sehingga meningkatkan nilai. Hal ini sesuai dengan penelitian yang dilakukan oleh Mangold dan Fauld (2009) yang menyatakan bahwa relevansi pribadi yang dibangun para produsen dan konsumen dapat mempengaruhi perilaku seseorang terhadap promosi. Pihak perguruan tinggi harus selalu meng-update tentang perkembangan perkuliahan di media sosial mereka.

Pengujian $\mathrm{H}_{2}$ membuktikan bahwa tidak ada pengaruh antara interactivity dengan keputusan pemilihan jurusan MBS. Hal ini menyatakan bahwa akun media sosial yang dimiliki oleh progdi MBS IAIN Surakarta kurang membangun komunikasi dengan para pengikutnya. Pengikut di media sosial tidak aktif memberikan komentar maupun berbagi berita berita dengan pengikut lain sehingga dapat menambah keputusan pemilihan mereka. Madu dan Madu (2002) menyatakan bahwa ketika website atau media sosial tidak terusa menerus diperbarui, maka tidak akan bisa memberikan kinerja yang diharapkan dan tidak memberikan nilai tambah bagi pengguna. Ketidakterdukungan hipotesis ini bisa dikarenakan karena kurang seringnya pihak kampus memperbarui infomasi tentang perkembangan kampus di media sosial. 
Hasil pengujian $\mathrm{H} 3$ menunjukkan bahwa terdapat pengaruh positif dan signifikan antara variable message dengan keputusan pemilihan progdi MBS IAIN Surakarta. Akun media sosial yang dimiliki progdi MBS IAIN Surakarta memposting informasi yang jelas dan mudah dipahami sehingga dapat menambah keputusan pemilihan program studi yang calon mahasiswa inginkan. Biasanya pengguna internet jarang membaca halaman internet secara detail tetapi hanya melihat secara sekilas halaman tersebut untuk mendapatkan informasi yang mereka inginkan (Madu dan Madu, 2002). Calon mahasiswa lebih menginginkan informasi yang lebih mudah dicerna dan diakses sehingga dapat membantu mereka dalam mengambil keputusan.

Pengujian H4 menunjukkan bahwa terdapat pengaruh positif dan signifikan antara Brand Familiarity dengan keputusan pemilihan progdi MBS IAIN Surakarta. Hal ini menyatakan bahwa ciri khas yang dimiliki progdi MBS IAIN Surakarta yang selalu memiliki perbedaan di bandingkan dengan program studi lain di mata para respoden. Ukuran kedekatan konsumen dengan merek dimana sebuah perusahaan yang cukup dikenal akan mendapatkan respon positif dibandingkan dengan merek baru (Mangolds \& Faulds, 2009).

\section{SIMPULAN DAN SARAN}

Berdasarkan tujuan penelitian serta analisa hipotesis penelitian dimana penulis ingin mengetahui pengaruh promosi melalui media sosial terhadap keputusan pemilihan pada progdi MBS IAIN Surakarta maka setelah diadakan pengujian berdasarkan data yang diperoleh melalui kuesioner dapat disimpulkan bahwa:

Pertama, ada hubungan yang erat antara calon mahasiswa dan pihak kampus MBS IAIN Surakarta melalui media sosial dengan respon yang cepat, pelayanan yang ramah dan aktif membahas informasi terbaru yang terjadi di kampus untuk membangun kepercayaan calon mahasiswa dalam menetapkan pilihan kuliahnya.

Kedua, informasi berupa pesan yang di posting di akun media sosial mampu menarik perhatian calon mahasiswa karena memberikan informasi yang jelas dan mudah 
dipahami. Dengan adanya gambar - gambar yang ditampilna juga dianggap sebagai sumber informasi yang memiliki daya tarik bagi mahasiswa baru.

Ketiga, dengan adanya daya tarik setelah melihat informasi, memunculkan rasa ingin tahu tentang produk yang ditawarkan. Oleh sebab itu, maka calon mahasiswa akan menghbungi kontak informasi, selain itu mereka juga akan memberikan komentar pada kolom komentar.

Saran yang diberikan adalah:

1. Pihak Progdi MBS IAIN Surakarta harus meningkatkan interkasi dengan calon mahasiwa bukan hanya sering memperbarui status, menginformasikan prosedur tata cara penerimaan mahasiswa baru dan mengajak calon mahasiswa baru, akan tetapi juga tim promosi pada Biro Marketing sebaiknya cepat dalam membalas dan menanggapi pertanyaan dari calon mahsiswa di media sosial. Hal ini dimaksudkan agar Progdi MBS IAIN bisa membangun kepercayaan dengan calon mahasiswanya.

2. Dengan segala keterbatasan baik dari segi waktu, jumlah responden, sumber keuangan, dll, peneliti menyadari kekurangan akan kesempurnaan dalam penelitian ini, diharapkan kepada peneliti selanjtnya untuk menggunakan faktor-faktor lain selain yang diteliti dalam penelitian ini seperti, eWOM, promosi berbayar, dan knowledge sharing.

\section{DAFTAR PUSTAKA}

APJII. (2017). Hasil Survei Penetrasi dan Perilaku Pengguna Internet Indonesia 2017. https://apjii.or.id/survei

Azmar, Azmar; Laksamana, Patria. Pengaruh social media promotion dan electronic word of mouth terhadap keputusan pemilihan pada perguruan tinggi. Jurnal Riset Perbankan Manajemen dan Akuntansi, [S.1.], v. 2, n. 2, p. 123-136, july 2018

Azwar, Saifuddin. 2000. Reabilitas dan Validitas. Yogyakarta: Pustaka Belajar

Bashar, A., Ahmad, I., \& Wasiq, M. (2012). Effectiveness Of Social Media As A Marketing Tool: An Empirical Study. International Journal of Marketing, 1(11), 88- 99. 
Campbell, D.E. and Wright, R.T. (2008) Shut-Up I Don't Care: Understanding the Role of Relevance and Interactivity on Consumer Attitudes toward Repetitive Online Advertising. Journal of Electronic Commerce Research, 9, 62-76.

Hautz, J., Fuller, K., Hutter, K., \& Thurridl, C. (2013). Let users generate your video ads? The impact of video source and quality on consumers' perceptions and intended behaviors. Journal of Interactive Marketing, 28(1), 1-15

Hawkins, N., Richards, P., Granley, H., \& Stein, D. (2004). The impact of exposure to the thin-ideal media image on women. Eating Disorders: The Journal of Treatment \& Prevention, 12(1), 35-50. Retrieved January 29, 2008, from PsycINFO database.

Javilvand (2012). The Effect of Electronic Word of Mouth On Brand Image and Purchase Intention: An Empirical Study in The Automobile Industry in Iran. Marketing Inteligence and Planning.

Kietzmann, J. H., Hermkens, K., McCarthy, I. P., \& Silvestre, B. S. (2011). Social media? Get serious! Understanding the functional building blocks of social media. Business horizons, 54(3), 241-251

Kietzmann, Jan and Hermkens, Kristoffer and McCarthy, Ian P. and Silvestre, Bruno, Social Media? Get Serious! Understanding the Functional Building Blocks of Social Media (November 5, 2014). Business Horizons, Vol. 54, No. 3, 2011. Available at SSRN: https://ssrn.com/abstract=2519365

Kim, Angella J. and Eunju Ko. (2012), "Do social media marketing activities enhance customer equity? An empirical study of luxury fashion brand", Journal of Business Research, No.65, pp.1480-1486

Kominfo. (2018)._Jumlah Pengguna Internet 2017 Meningkat, Kominfo Terus Lakukan Percepatan Pembangunan Broadband. https://kominfo.go.id

Kotler dan Amstrong. (2008). Prinsip-Prinsip Pemasaran. Jilid 1 dan 2. Edisi 12. Jakarta: Erlangga.

Madu, C.N., \& Madu, A.A. (2002). Dimensions of Equality. International Journal of Quality and Reliability Management,19(3), 246-258.

Mangold, W.G., Faulds, D.J. (2009). Social Media: The New Hybrid Element of the Promotion Mix. Business Horizons, 52(1) 357-365.

Nurohman. Y. A dan Qurniawati. R. S. (2017). Pengaruh Komunikasi Media sosial Terhadap Persepsi Konsumen Pada Produk Kosmetik Halal. Jurnal Among Makarti Vol.10, No.19: STIE AMA Salatiga

Reuters Institute. (2017). Digital News Reports. https://reutersinstitute.politics.ox.ac.uk

Roscoe, J.T. 1975. Fundamental Research Statistics for the Behavioral Sciences. (2nd Ed.). New York: Holt, Rinehart and Winston

Peran Promosi Media Sosial Pada Pemilihan Program Studi Manajemen Bisnis Syariah (Yulfan Arif Nurohman, Alvin Yahya, Rina Sari Qurniawati) 
Sikape, H.J. (2014), Persepsi Komunikasi Pengguna Media Sosial Pada Blackberry Messenger Twitter dan Facebook oleh Siswa SMAN 1 Tahuna. Jurnal Acta Diurna, 3 (3).

Zubair. A. (2010). Fenomena Facebook: Keterlibatan Teknologi Komunikasi Dalam Perkembangan Komunikasi Manusia. Jurnal Aspikom: Vol 1 Nomor 1. 